\title{
From Campus to Congress: Navigating Policy, Procedure, and Politics as an AMS Congressional Fellow
}

\section{Catherine Paolucci}

Each year, the AMS funds a Congressional Fellowship within the Science and Technology Policy Fellowship program run by the American Association for the Advancement of Science (AAAS). Approximately 35 Congressional Fellows are sponsored by professional organizations in a range of scientific fields, including chemistry, physics, geology, engineering, meteorology, and others. Fellows spend a year working for a member of Congress or a Congressional committee, with the aim of bringing scientific perspectives into the legislative process.

During the 2016-2017 academic year, I had the honor of serving as the 12th AMS Congressional Fellow. The fellowship began with an intensive orientation designed to help bridge the transition from academia to government service. Experts shared insight on all three branches of government, Congressional procedures, legislative processes, the federal budget, and appropriations. A placement process followed, and I was excited to accept a position in the office of Senator Al Franken (MN).

I joined Senator Franken's staff as an Education Policy Fellow, with a specific focus on issues in higher education. Even with a strong education background at both the K-12 level and in higher education, I quickly realized how much there was still to learn about education policy!

Catherine Paolucci is associate professor in the Department of Mathematics and the Department of Teaching and Learning at the State University of New York at New Paltz. Her email address is paoluccic@gmai1.com.

Received October 17, 2017.

For permission to reprint this article, please contact: reprint-permission@ams . org.

DOI: http://dx.doi.org/10.1090/noti1628
The mutually beneficial nature of the fellowship allowed me to offer insight from the field, while gaining valuable first-hand experience navigating policy, procedure, and politics on Capitol Hill.

As a member of the Senator's staff, my daily responsibilities included researching and analyzing legislation to help advise the Senator, attending briefings on current and emerging issues, writing memos to brief the Senator, supporting him at committee hearings and events, drafting letters on education issues, meeting with constituents and stakeholders, and liaising with the Department of Education. Working for a Senator on the Health, Education, Labor, and Pensions (HELP) Committee also meant collaborating with other HELP Committee members' staff, and gaining first-hand experience with the critical role of Congressional committees.

The Presidential transition played a significant role in shaping a large portion of my work. The first few months of the new Administration were devoted to hearings and votes on cabinet nominees and reviewing regulations that were eligible to be overturned by the Congressional Review Act (CRA). Working for a Senator in the minority meant that much of what we did during this period was reactive. Our efforts were focused on helping the Senator respond to things that were happening in a way that was important to him and his constituents, including nominees for federal roles, executive orders, budget proposals, appropriations, and regulation changes.

The latter months of my fellowship offered more opportunities to help write and introduce legislation, including two new bills supporting career and technical education and teacher education. Through these efforts, I learned 
what it takes to reach agreement on a bi-partisan bill and how to navigate the politics of policy to help ensure that a bill has the best possible opportunity to become law.

The opportunity to engage directly in so many aspects of Congress meant learning something new every day! The following are some key lessons that capture some of this valuable insight:

\section{Lesson \#1: Politics and procedure are driving forces in policy.}

As academics, we are trained to carefully craft our research, writing, teaching, and public statements to ensure that they are grounded in theory and informed by research. The biggest misconception I brought to my fellowship was that the same would apply to policy. In Congress, even the most basic ideas are almost always political. I think the hardest lesson was learning just how differently people view and make sense of important issues. Part of this lesson was realizing that clinging to the way I understand something will not allow me to successfully help others to share my vision. Instead, it's often more effective to understand what motivates them, and find a way to frame an issue or proposed solution that aligns with their value system.

In addition, as a mathematics community, we broadly embrace the notion that an argument based on evidence or proof will be sufficiently compelling to those with whom we are discussing an issue. Working with Congressional Fellows from over 15 other scientific fields convinced me that this is also true for the broader scientific community. However, for those outside of our disciplines, and particularly those who are positioned to make decisions impacting the future of our work, the facts must be personalized and presented in way that will resonate. This brings me to my next lesson.

\section{Lesson \#2: Constituents and key stakeholders in a Member's state or district have their ear.}

As simple as it seems, it is essential to remember that the job of a Member is to represent the people in their state or district. In fact, this is also their key to getting re-elected. So, constituents are often in the best position to influence the policy decisions and priorities of a particular Member. This has two key implications. First, if an issue is important to a national community, localized grassroots efforts in which people engage directly with their own Senators and Representatives can be powerful. Second, when national societies, agencies, or organizations advocate as a voice for their members, it is critical that they customize their message. For instance, when approaching Senators about an issue, it is essential to include details about the issue's specific impact on their state's economy, job market, education system, health care, etc. This is often an effective way to foster bipartisan collaboration.

\section{Lesson \#3: Committee assignments impact a Member's influence on particular issues.}

While Members have wide-ranging priorities, their capacity to impact an issue area is greater if they are on the committee that deals with this issue. During my time in Senator Franken's office, his service on the Senate HELP Committee, Judiciary Committee, Energy and Natural Resources Committee, and Indian Affairs Committee placed him at the center of critical conversations about issues in education, healthcare, energy, and the environment. Committee members are the ones who ask critical questions of nominees or witnesses during hearings, and they have the opportunity to shape and amend proposed legislation before sending it out for a full vote.

\section{Lesson \#4: Congress does a lot more than most people think.}

While passing legislation is one important job of Congress, an equally important part of their job is preventing potentially harmful bills from becoming law. Legislation is often dense and written in legal language that does not make for light reading! Plus, there are thousands of bills introduced each Congress, making it virtually impossible for every Member to know what is in every piece of proposed legislation. This is why it is important for Members to not just hear from staff, constituents, and advocates about the bills they should support, but also hear about any potentially harmful impacts of proposed legislation that may be nuanced or buried within a seemingly good message.

Members can also

the notion that an argument based on evidence or proof will be sufficiently compelling

be the voice of their constituents through formal letters to the President, federal agencies, the Supreme Court, large corporations, etc. These include individual letters on a local issue, state delegation letters from all House and Senate members from a particular state, committee letters from members of a Senate or House committee, caucus letters from a large portion of the members of a specific party, and bipartisan letters from members on both sides of the aisle. There are also appropriations letters written to the Appropriations Committee with funding requests for federal agencies and programs.

\section{Lesson \#5: The AMS Congressional Fellowship is a powerful way to enhance your career and bring your professional experience and mathematical perspectives to Congress.}

While opportunities to directly apply mathematical expertise vary by placement, in my position, I found myself constantly drawing on my years of experience working with students, teachers, and other colleagues in academic communities. During my time in the office, Senator Franken cosponsored a broad range of important legislation related to college access and affordability and led the development of new legislation supporting innovations in career and technical education and teacher education. It 


\section{COMMUNICATION}

was extremely rewarding to work for a Senator who valued my background and experience and welcomed my voice in conversations about these issues.

In addition to my experience in the Senate, the fellowship also offered opportunities to become a more active and engaged member of the AMS. I am grateful to the AMS for this incredible opportunity and inspired by the AMS's commitment to strengthening the mathematics community's voice on important issues that will affect the future of mathematics research and education.

\section{Photo Credit}

Photo of Catherine Paolucci by Chris Paolucci.

EDITOR'S NOTE. Applications for the AMS Congressional Fellowship from September 2018 to August 2019, with a stipend of US $\$ 79,720$, are due by February 15, 2018. See www.ams . org/programs/ams-fe11owships/ams-aaas/ams-aaas-congressiona 1-fe1Towship.

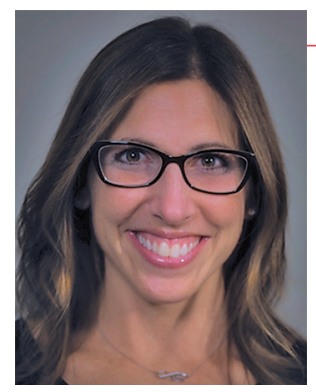

\section{ABOUT THE AUTHOR}

Catherine Paolucci's research interests support program and policy development for mathematics teacher education. Her work has focused on the evaluation and development of teachers' mathematical knowledge, innovative ways to increase engagement in STEM education, and the role of outreach and social impact in teacher preparation.

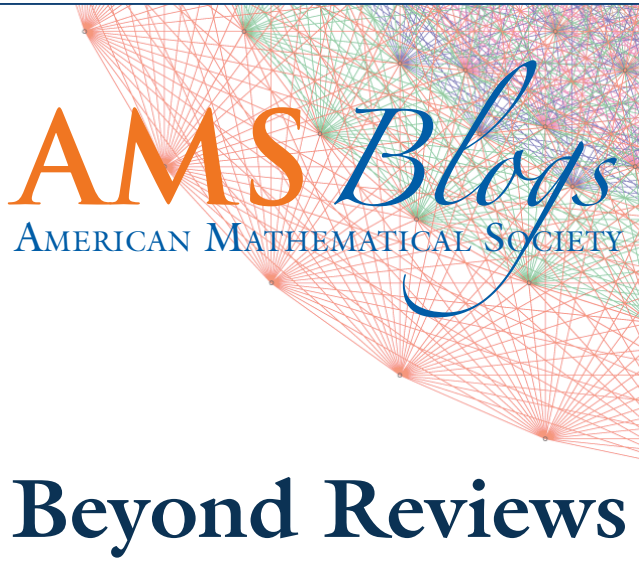

A blog about MathSciNet ${ }^{\circ}$

From the Executive Editor of

Mathematical Reviews, Edward Dunne

A blog created to highlight the innovative features of MathSciNet. Updates will include particularly informative reviews and will discuss tips and tricks for navigating MathSciNet, all with the goal of being helpful to users both old and new.

\section{blogs.ams.org/beyondreviews}

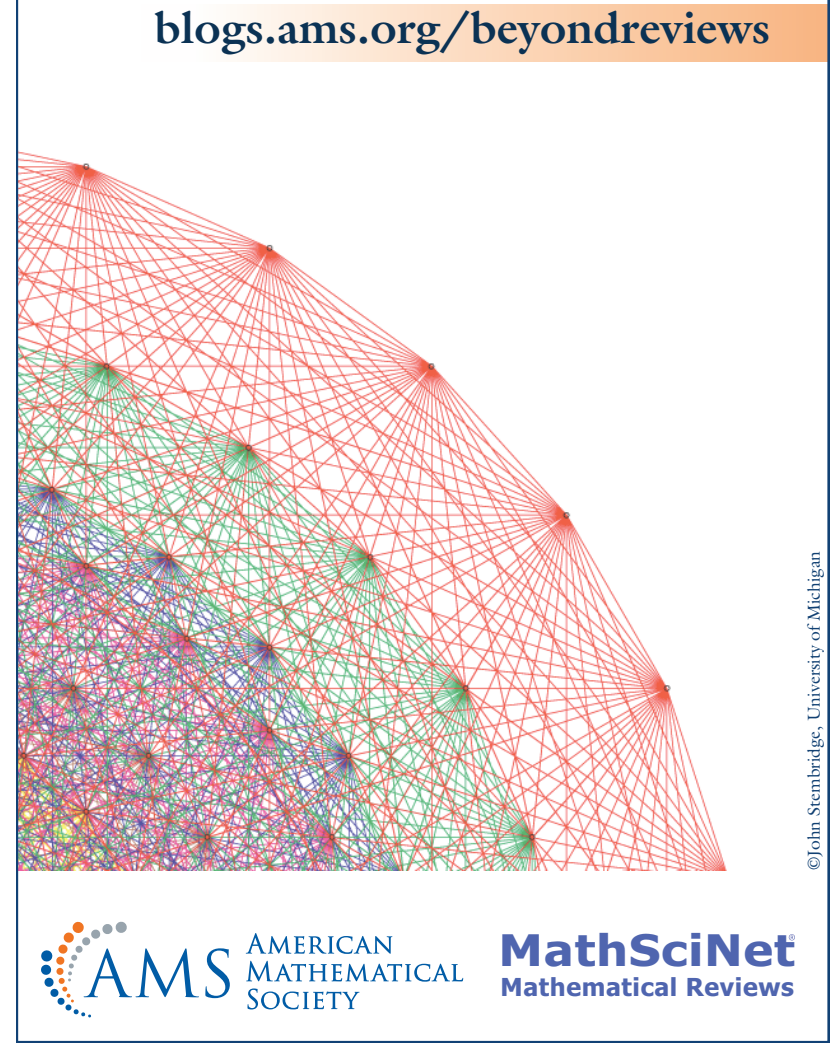

